\title{
Canadian Epileptologists' Counseling of Drivers Amidst Guideline Inconsistencies
}

\author{
Jeffrey Jirsch, Donald W. Gross, Nathalie Jette, Paolo Federico, Francois \\ Dubeau, Jose F. Tellez-Zenteno, Bernd Pohlmann-Eden, Jorge G. Burneo, \\ Richard McLachlan, Syed N. Ahmed, Charles Deacon, Manouchehr Javidan, \\ Dang K. Nguyen, R. Mark Sadler, Allison Spiller, Tiffany Townsend, \\ Martin Veilleux, Richard A. Wennberg, Samuel Wiebe, Alexei Yankovsky
}

\begin{abstract}
Background: Epilepsy is a common medical condition for which physicians perform driver fitness assessments. The Canadian Medical Association (CMA) and the Canadian Council of Motor Transportation Administrators (CCMTA) publish documents to guide Canadian physicians' driver fitness assessments. Objectives: We aimed to measure the consistency of driver fitness counseling among epileptologists in Canada, and to determine whether inconsistencies between national guidelines are associated with greater variability in counseling instructions. Methods: We surveyed 35 epileptologists in Canada (response rate $71 \%$ ) using a questionnaire that explored physicians' philosophies about driver fitness assessments and counseling practices of seizure patients in common clinical scenarios. Of the nine scenarios, CCMTA and CMA recommendations were concordant for only two. Cumulative agreement for all scenarios was calculated using Kappa statistic. Agreement for concordant (two) vs. discordant (seven) scenarios were split at the median and analyzed using the Wilcoxon signed rank sum test. Results: Overall the agreement between respondents for the clinical scenarios was not acceptable (Kappa=0.28). For the two scenarios where CMA and CCMTA guidelines were concordant, specialists had high levels of agreement with recommendations ( $89 \%$ each). A majority of specialists disagreed with CMA recommendations in three of seven discordant scenarios. The lack of consistency in respondents' agreement attained statistical significance ( $<<0.001)$. Conclusions: Canadian epileptologists have variable counseling practices about driving, and this may be attributable to inconsistencies between CMA and CCMTA medical fitness guidelines. This study highlights the need to harmonize driving recommendations in order to prevent physician and patient confusion about driving fitness in Canada.
\end{abstract}

RÉSUMÉ: Conseils donnés aux conducteurs par les épileptologues canadiens compte tenu des divergences existantes entre les lignes directrices. Contexte : L'épilepsie est un problème médical fréquent pour lequel les médecins sont appelés à déterminer l'aptitude à conduire de leurs patients. L'Association médicale canadienne (AMC) et le Conseil canadien des administrateurs en transport motorisé (CCATM) publient des documents à l'intention des médecins canadiens pour les renseigner sur l'évaluation de l'aptitude à conduire de leurs patients. Objectifs : Notre but était de mesurer les divergences dans le counseling concernant l'aptitude à conduire parmi les épileptologues au Canada et de déterminer si les divergences entre les lignes directrices nationales sont associées à une plus grande variabilité dans leurs consignes. Méthode : Nous avons effectué un sondage auprès de 35 épileptologues du Canada (taux de réponse de 71\%) au moyen d'un questionnaire explorant la philosophie des médecins au sujet de l'évaluation de l'aptitude à conduire et de leurs pratiques de counseling des patients épileptiques au moyen de scénarios fréquents en clinique. Les recommandations du CCATM et de l'AMC étaient concordantes pour seulement deux des neuf scénarios. L'accord cumulé pour tous les scénarios a été calculé au moyen de la statistique Kappa. La médiane a été utilisée pour diviser les scénarios concordants (deux) versus les scénarios discordants (sept) et le test de la somme des rangs de Wilcoxon a été utilisé pour en effectuer l'analyse. Résultats : Globalement, l'accord entre les répondants concernant les scénarios cliniques n'était pas acceptable (kappa = 0,28). Pour les deux scénarios où les lignes directrices de l'AMC et du CCATM étaient concordantes, les spécialistes exprimaient un haut niveau d'accord avec les recommandations (89\% chacun). La majorité des spécialistes n'était pas d'accord avec les recommandations de l'AMC dans trois des sept scénarios discordants. Le manque de cohérence dans l'accord des répondants était significatif au point de vue statistique $(\mathrm{p}<0,001)$. Conclusions : Les épileptologues canadiens ont des pratiques de counseling très variables concernant la conduite de véhicules motorisés et le manque de cohérence entre les lignes directrices de l'AMC et du CCATM concernant l'aptitude médicale à conduire pourrait en être la cause. Cette étude souligne la nécessité d'harmoniser les recommandations concernant la conduite afin d'éviter la confusion à ce sujet chez les médecins et les patients au Canada.

Can J Neurol Sci. 2014; 41: 413-420

From the Division of Neurology (JJ, DWG, SNA), University of Alberta, Edmonton; Department of Clinical Sciences and Hotchkiss Brain Institute, Department of Community Health Sciences and Institute for Public Health (NJ, PF, SW), University of Calgary, Calgary, Alberta; Montreal Neurological Institute (FD, MV), McGill University; Division of Neurology (DKN), University of Montreal, Montreal; Division of Neurology (CD), University of Sherbrooke, Sherbrooke, Quebec; Division of Neurology (JFTZ), University of Saskatchewan, Saskatoon, Saskatchewn; Department of Clinical Neurological Sciences (JGB, RM), University of Western Ontario, London; Division of Neurogy (AS), Queen's

University, Kingston; Division of Neurology (RAW), University of Toronto, Toronto, Ontario; Division of Neurology (MJ, TT), University of British Columbia, Vancouver, B.C.;

Division of Neurology (BPE, RMS), Dalhousie University, Halifax, Nova Scotia; Division of Neurology (AY), University of Manitoba, Winnipeg, Manitoba, Canada.

Received October 29, 2013. Final Revisions SubmitTed March 4, 2014.

Correspondence to: J. Jirsch, 2E3-31 WMC, 8440-112 St, Edmonton, Alberta, Canada. Email: jeff.jirsch@ ualberta.ca. 
Physicians are entrusted to identify and warn patients who are unsafe to drive for the patients' sake and for the better public good $^{1-3}$. Ineffectual driving restriction policies, however, can severely limit patients' socialization and harm the patientphysician relationship ${ }^{4}$. The variety of medical conditions and circumstances that can impact driving performance is broad, and physicians depend heavily upon guidelines to inform their driving recommendations ${ }^{5,6}$. In Canada, there has been much effort to standardize driver fitness decision-making nationally, and for commercial drivers to align recommendations with United States policy. The Canadian Council of Medical Transport Administrators (CCMTA) Medical Standards for Drivers $^{7}$ were developed by Transportation officials in conjunction with medical experts as a guide to establish basic medical qualifications to drive, and are intended for use by both physicians and driver fitness authorities. Along with the CCMTA standards, the Canadian Medical Association (CMA) has published the Guide to Determine Medical Fitness to Operate Motor Vehicles which is intended to assist physicians in counseling their patients about the effects that their medical conditions have on their fitness to drive and how to minimize these effects ${ }^{8}$. The CMA guide also intends to help physicians in determining whether a person is medically fit and to identify conditions that will likely disqualify a person from holding a license. Therefore in Canada there are two published documents targeted at physicians, which provide Canadian medical fitness guidelines for driving.

Seizures and epilepsy are common conditions that potentially impact driver fitness. Several inconsistencies between CCMTA and CMA guidelines have previously been identified for patients with epileptic seizures ${ }^{9}$. For example, a non-commercial driver with a standard driver's permit who has experienced a single unprovoked seizure based on CCMTA recommendations is considered fit to drive if a detailed neurological assessment and electroencephalogram (EEG) are satisfactory. The CMA recommendations however require the patient to also have normal neurologic imaging and remain seizure-free for at least three months before being deemed fit to drive. In the case of a patient presenting to the emergency room after having a single unprovoked seizure where the neurologic assessment as well as EEG are normal, the patient meets CCMTA fitness requirements but remains medically unfit based on CMA recommendations for another three months. For the physician assessing this seizure patient in the emergency room, the conflicting CMA and CCMTA guidelines create confusion. Inconsistencies between regulations are not unique to Canada as one epilepsy expert in the United States described the situation as a "confusing mix of federal and state laws, regulations, and local practices that vary widely" 10 .

Table 1: National and provincial published driving fitness guidelines for a sample of common seizure patient scenarios in Canada

\begin{tabular}{|c|c|c|c|c|}
\hline & $C M A$ & CCMTA & $\begin{array}{c}\text { Quebec Highway } \\
\text { Safety Code }\end{array}$ & $\begin{array}{c}\text { British Columbia Driving } \\
\text { Fitness Guide } \\
\end{array}$ \\
\hline $\begin{array}{l}\text { New epilepsy diagnosis involving } \\
\text { private driver with class } V \\
\text { license* }\end{array}$ & $\begin{array}{l}\text { Drive only if } 6 \text { months } \\
\text { seizure-free and } \\
\text { compliant on anti- } \\
\text { seizure drug }\end{array}$ & $\begin{array}{l}\text { Drive only if } 6 \\
\text { months seizure-free } \\
\text { and compliant on } \\
\text { anti-seizure drug }\end{array}$ & $\begin{array}{l}\text { Drive only if } 6 \text { months } \\
\text { seizure-free (discretionary } \\
\text { power of physician, } \\
\text { otherwise } 12 \text { months) }\end{array}$ & $\begin{array}{l}\text { Drive only if } 6 \text { months seizure-free } \\
\text { and compliant on anti-epileptic } \\
\text { medications }\end{array}$ \\
\hline $\begin{array}{l}\text { New epilepsy diagnosis in } \\
\text { commercial driver, with class } 1-4 \\
\text { driver's license* }\end{array}$ & $\begin{array}{l}\text { Drive only if } 5 \text { years } \\
\text { seizure-free }\end{array}$ & $\begin{array}{l}\text { Drive only if } 5 \\
\text { years seizure-free } \\
\text { and favorable report } \\
\text { from a physician }\end{array}$ & $\begin{array}{l}\text { Drive only if } 5 \text { years } \\
\text { seizure-free }\end{array}$ & $\begin{array}{l}\text { Drive only if } 5 \text { years seizure-free } \\
\text { continuously on anti-seizure drug, or, } \\
5 \text { years seizure-free continuously off } \\
\text { anti-seizure drug }\end{array}$ \\
\hline $\begin{array}{l}\text { Single unprovoked seizure with } \\
\text { loss of awareness (private } \\
\text { driver/class V license) ** }\end{array}$ & $\begin{array}{l}\text { Drive only if } 3 \text { months } \\
\text { seizure-free and a } \\
\text { neurological assessment } \\
\text { (including EEG and } \\
\text { neuro-imaging) has } \\
\text { been carried out }\end{array}$ & $\begin{array}{l}\text { Drive only if } \\
\text { satisfactory } \\
\text { neurological } \\
\text { assessment and } \\
\text { EEG }\end{array}$ & $\begin{array}{l}\text { Drive only if the cause } \\
\text { remains unknown after } \\
\text { investigation by a } \\
\text { neurologist and an EEG } \\
\text { shows no epileptiform } \\
\text { activity }\end{array}$ & $\begin{array}{l}\text { Drive only if } 3 \text { months seizure-free } \\
\text { and a medical specialist has } \\
\text { determined that epilepsy is not } \\
\text { diagnosed }\end{array}$ \\
\hline $\begin{array}{l}\text { Juvenile Myoclonic Epilepsy } \\
\text { diagnosis** }\end{array}$ & $\begin{array}{l}\text { No driving of any } \\
\text { vehicle unless taking } \\
\text { anti-seizure drug }\end{array}$ & $\begin{array}{l}\text { Not specifically } \\
\text { addressed }\end{array}$ & Not specifically addressed & Not specifically addressed \\
\hline $\begin{array}{l}\text { Epilepsy patient (private/class } V \\
\text { license) undergoes a prescribed } \\
\text { anti-seizure drug adjustment } * *\end{array}$ & $\begin{array}{l}\text { Drive only if } 3 \text { months } \\
\text { seizure-free after } \\
\text { medication is last } \\
\text { changed }\end{array}$ & $\begin{array}{l}\text { Not specifically } \\
\text { addressed }\end{array}$ & Not specifically addressed & $\begin{array}{l}\text { Drive only if seizure-free } 3 \text { months } \\
\text { after medication is last changed }\end{array}$ \\
\hline $\begin{array}{l}\text { Epilepsy patient (private/class } V \\
\text { license) has a seizure recurrence } \\
\text { after a prescribed anti-seizure } \\
\text { drug change or withdrawal }{ }^{* *}\end{array}$ & $\begin{array}{l}\text { Drive only if previously } \\
\text { effective medication is } \\
\text { resumed and } 3 \text { months } \\
\text { seizure-free }\end{array}$ & $\begin{array}{l}\text { Drive only if } \\
\text { previous medication } \\
\text { is resumed }\end{array}$ & $\begin{array}{l}\text { Drive only if previous } \\
\text { medication is resumed and } \\
3 \text { months seizure-free }\end{array}$ & $\begin{array}{l}\text { Drive only if a previously effective } \\
\text { treatment regime is re-established } \\
\text { and the treating physician indicates } \\
\text { that further seizures are unlikely }\end{array}$ \\
\hline $\begin{array}{l}\text { Epilepsy patient (private/class } V \\
\text { license) has an epilepsy } \\
\text { surgery** }\end{array}$ & $\begin{array}{l}\text { Drive only if } 12 \text { months } \\
\text { seizure-free after } \\
\text { surgery and with } \\
\text { therapeutic drug levels }\end{array}$ & $\begin{array}{l}\text { Not specifically } \\
\text { addressed }\end{array}$ & Not specifically addressed & $\begin{array}{l}\text { Drive only if } 6 \text { months seizure-free } \\
\text { after surgery and compliant with } \\
\text { physician's advice }\end{array}$ \\
\hline
\end{tabular}

* CMA and CCMTA guidelines are concordant. ** CMA and CCMTA guidelines are discordant 
If the ultimate objective is to develop a consistent approach to driver fitness across the country (CCMTA), it is critical that physicians, along with licensing authorities have a consistent approach in dealing with issues related to medical fitness. It is our hypothesis that discordant recommendations in the CMA and CCMTA fitness guidelines create inconsistencies in physicians' evaluation of drivers' medical fitness. The first objective of this study was to evaluate the consistency of Canadian epilepsy specialists in their approach to common clinical questions regarding medical fitness and seizures. A secondary aim was to determine whether discordance between the CMA and CCMTA guidelines is associated with greater variation in counseling seizure patients by epilepsy physicians.

\section{MethodS}

A panel of study investigators was assembled from tertiary care epilepsy centers across Canada. Investigators devised a protocol and survey designed to examine epilepsy specialists' counseling practices and attitudes towards the management of driving safety. Canadian epileptologists were chosen as our study group rather than a more broad sampling of non-specialized physicians because of the reduced variability in clinical practice expected among experts. The study protocol was approved by the University of Alberta Research Ethics Office.

Potential participants were identified and their contact information obtained from 2013 Canadian League Against Epilepsy and American Epilepsy Society membership lists. Eligibility criteria were active members, who were medical doctors with Canadian contact addresses. Individuals were excluded if their practice involved mainly children. A list of potential participants was circulated among study investigators located across Canada, and potential subjects were added or omitted based on knowledge of the investigator group. Potential participants also included members of the panel of study investigators but investigator participants were blinded to others' responses. In April 2013, potential participants were contacted by email and invited to participate in the web-based survey, and a second e-mail was sent two weeks later. Implied consent was inferred if participants responded to the email. Recruitment ended in June 2013.

A questionnaire comprising 22 items (see Appendix A) was designed to explore demographic details (questions (q) 1-4), management philosophies (q.5-11), as well as practice patterns (q.12-22). Nine common clinical scenarios were developed involving epilepsy patients (q.12,14,16-22), and physicians were asked about their counseling instructions following each vignette. In all nine scenarios, physicians were asked whether they counseled patients in agreement with CMA guidelines. Two scenarios involved counseling instructions where CMA and CCMTA national guidelines are concordant $(\mathrm{q} 12,14)$ and seven scenarios involved scenarios where the guidelines are discordant (q.16-22; see Table 1). Two items identified whether physicians provided accurate information to patients regarding eligibility criteria to hold a driver's license in their province derived from the CCMTA document. Participants were asked to identify which documents they used to counsel patients (e.g. CCMTA ${ }^{7}, \mathrm{CMA}^{8}$, British Columbia (BC) Driver Fitness Handbook ${ }^{11}$, Code de la Sécurité Routière du Québec $(\mathrm{QC})^{12}$; Table 1). If the respondent indicated that he/she used provincial Transportation criteria without naming the document, study investigators inferred that the CCMTA guidelines was being utilized if the relevant province's website indicated specifically such.

\section{Data Analysis}

The percentage of respondents that counseled in a manner that agreed with CMA guidelines was calculated for all nine scenarios. Agreement between respondents was calculated using Kappa statistic and deemed acceptable at a threshold of $>0.6$. Cumulative agreement to concordant vs. discordant scenarios were split at the median (1 and 3, respectively) and analyzed using the Wilcoxon signed rank sum test. Since $\mathrm{BC}^{11}$ and $\mathrm{QC}^{12}$ both have unique published medical standards for assessing fitness to drive in patients with epilepsy, analyses were repeated after excluding BC and QC. Significance was set at $\mathrm{p}<0.05$. Analyses were carried out using Stata 11 (Stata Corp., College Station, TX). Only responses provided by physicians with an active clinical practice in adult neurology were included in analyses. Duplicate or incomplete responses were excluded.

\section{RESULTS}

\section{Demographics and Characteristics of Respondents}

Of the 59 potential participants located in eight provinces that were identified and invited to participate in the study, 42 (71.2\%) responded. Of these, seven were excluded from analyses (three recently retired from clinical practice, one had a primary practice in pediatric neurology, and three had incomplete questionnaires). Among 35 participants with complete data, 33 (94\%) had

Table 2: Characteristics of Canadian experts in epilepsy with active clinical practice in Adult Neurology $(n=35)$

\begin{tabular}{lc}
\hline & All provinces $(\mathrm{n}=35)$ \\
\cline { 2 - 2 } Epilepsy subspecialty training & $\mathrm{n}(\%)$ \\
Province located & $33(94.3)$ \\
British Columbia & \\
Alberta & $4(11.4)$ \\
Saskatchewan & $10(28.6)$ \\
Manitoba & $2(5.7)$ \\
Ontario & $1(2.9)$ \\
Quebec & $8(22.9)$ \\
Nova Scotia & $7(20.0)$ \\
Resources used to counsel patients & $3(8.6)$ \\
CMA only & \\
CCMTA only & $14(40.0)$ \\
CMA and CCMTA & $5(14.3)$ \\
Neither CMA nor CCMTA & $9(25.7)$ \\
CMA/CCMTA and Other & $4(11.4)$ \\
\hline
\end{tabular}




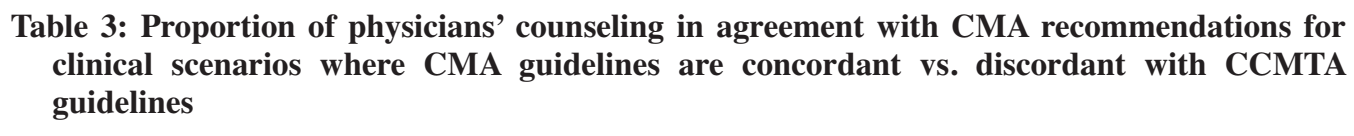

\begin{tabular}{lc}
\hline & $\begin{array}{c}\text { All provinces } \\
\text { (n=35) }\end{array}$ \\
\cline { 2 - 2 } No driving $\geq 6$ months with Class V license after diagnosis of epilepsy & $\mathrm{n}(\%)$ \\
\hline No driving $\geq 5$ years with Class I license after diagnosis of epilepsy & $31(88.6)$ \\
CMA and CCMTA guidelines are discordant & $31(88.6)$ \\
Patients should not drive for a period of time after a first seizure & $32(91.4)$ \\
Patients need neuro-imaging after a first seizure before being allowed to drive & $26(74.3)$ \\
JME patients should always remain on anti-seizure medications in order to be fit to drive & $10(28.6)^{\Psi}$ \\
Epilepsy patients should not drive $\geq 3$ months after any anti-seizure medication adjustment & $12(34.3)^{\Psi}$ \\
$\begin{array}{l}\text { Epilepsy patients withdrawn from medication should refrain from } \\
\text { driving for a period of time after seizure recurrence }\end{array}$ & $29(82.9)$ \\
Patients should not drive for at least 12 months after epilepsy surgery & $19(54.3)$ \\
Patients require therapeutic drug levels following epilepsy surgery in order to drive & $8(22.9)^{\Psi}$ \\
\hline
\end{tabular}

$\Psi$ : Majority of respondents' counseling not consistent with CMA recommendations

subspecialty training in epilepsy (Table 2). Participants were located in seven Canadian provinces, and 24 (68\%) were from the four provinces with discretionary reporting. Overall, $89 \%$ used the CCMTA or CMA guidelines in their practice. Respondents who used guidelines other than the CMA or CCMTA documents practiced in either BC or QC, and all of these individuals used published provincial standards in these two provinces.

\section{Driving Fitness Instructions in Case Scenarios}

Participants reported their agreement with counseling of epileptic seizure patients in common clinical scenarios (Table 3). Agreement between respondents for all nine scenarios calculated using Kappa statistic was 0.28 , below the study threshold for being acceptable. Kappa agreement among respondents from mandatory-reporting provinces $(0.153)$ and discretionaryreporting provinces $(0.326)$ were also not acceptable (NS). For the two scenarios where the CMA and CCMTA guidelines are concordant, $89 \%$ of all respondents agreed with each of the two scenarios. For the seven scenarios where the CMA and CCMTA guidelines are discordant, physicians agreed with CCMTA recommendations in three scenarios, and agreed with CMA recommendations in four scenarios. Among the seven discordant clinical scenarios, only one attained a level of agreement equal or superior to the two concordant scenarios. The average agreement with CMA guidelines when recommendations were concordant with CCMTA guidelines was $89 \%$ versus $56 \%$ when the two guidelines were discordant. Cumulative responses with the seven discordant scenarios showed that respondents exhibited lack of consistency in their agreement with the discordant scenarios that attained statistical significance (Table 4). The analysis was repeated with the exclusion of respondents from the provinces of Quebec and British Columbia and again statistical significance was attained (data not shown).

\section{Physician Opinion About Driver Fitness and Their Role in Driving Assessment}

All 35 participants were asked about their personal philosophies with respect to medical fitness and driving. Thirty participants $(86 \%)$ agreed with the statement "If a patient is medically unfit to drive, they should be ineligible to hold a valid driver's permit", 32 (91\%) agreed with the statement "It is the physician's role to provide accurate information to the provincial registry but it is the registry's role to determine whether a patient is eligible to hold a driver's license", and 28 (80\%) agreed with the statement "It is the physician's obligation to provide patients with accurate information regarding what rules are used by the provincial registry to determine eligibility to hold a driver's license."

\section{DISCUSSION}

Road traffic injuries are the leading cause of death for young people aged 15-29 years and the eighth leading cause of death globally ${ }^{13}$. Although many patients with medical conditions are safe to operate a motor vehicle, for some their medical condition causes disability which results in significant risk of accidents. In order to prevent avoidable accidents, the development of medical standards for drivers is essential. The stated primary 


\section{Table 4: Consistency in agreement with clinical scenarios on driving fitness decisions when CMA} guidelines are concordant vs. discordant with CCMTA guidelines*

\begin{tabular}{lc}
\hline & $\begin{array}{c}\text { All provinces } \\
(\mathrm{n}=35)\end{array}$ \\
\hline CMA and CCMTA guidelines are concordant & $\mathrm{n}(\%)$ \\
$0-1$ & $7(20.0)$ \\
2 & $28(80.0)$ \\
CMA and CCMTA guidelines are discordant & $18(51.4)$ \\
$1-3$ & $17(48.6)$ \\
4 or more & $<0.001$ \\
p-value & \\
\hline * Cumulative agreement to concordant vs. discordant scenarios were split at the median $(1$ and 3, respectively) and ana- \\
lyzed using the Wilcoxon signed rank sum test
\end{tabular}

purpose of the CCMTA Medical Standards for Drivers is "to provide driver fitness authorities with research-based information and standards to support consistent driver fitness decisions within, and across, Canadian jurisdictions"7. In all Canadian jurisdictions, final decisions on driver fitness are made by provincial licensing bodies. If national standards are adopted, medical fitness decisions can be expected to be consistent at the level of the licensing body regardless of jurisdiction. Physicians also play a critical role in the process of assessing fitness: 1) they provide patients information on whether driving with a medical condition poses a risk to the individual or public, and 2) they provide provincial licensing authorities accurate information about patients' functional deficits, diagnoses, and prognoses. The primary finding of this study is that epilepsy specialists in Canada are providing patients with highly variable information regarding medical fitness for driving. Patients therefore are receiving inconsistent information regarding eligibility to hold a driver's permit, not only between but also within jurisdictions. If individuals are told by one physician that they are not medically fit to drive, and advised by another that they are medically fit, consistent driver fitness decisions become impossible to achieve.

Prior studies have shown that non-neurologist physicians in several Western countries have variable counseling practices for drivers with epilepsy ${ }^{14-17}$. Neurologists appear to be more likely to counsel their seizure patients about driving than nonneurologists ${ }^{18}$. However, the content of their counseling is variable within countries ${ }^{19,20}$ and even within states or provinces with more uniform driving regulations and practice guidelines ${ }^{18,21}$. In general, clinical practice guidelines are poorly implemented by physicians because guidelines are perceived to be restrictive to physician autonomy, and frequently impractical for the management of individual cases ${ }^{22,23}$. Our study suggests that another challenge to the successful implementation of clinical practice guidelines exists where relevant guidelines are discordant. Multiple CMA and CCMTA recommendations are in frank disagreement for seizure patients, and we have found that epilepsy specialists demonstrate less consistency in agreement in scenarios where discordance is present. While we have found an association, we have not been able to establish through this study that discrepancies between guidelines are causally-linked to physicians' variability in driver counseling. An alternative plausible explanation for epileptologists' variability in driver counseling may be that physicians have pre-formed opinions that differ from Canadian guidelines, and physicians may be knowledgeable of but choose not to follow specific recommendations. However, for this alternative explanation to fully explain the variability that we measure in our study, one must assume that guidelines with legal local relevance have little effect on specialist physicians' practices.

Canadian provincial Transportation Administrators (similar to other Western countries ${ }^{24,25}$ ), have made efforts to harmonize medical eligibility recommendations for drivers through the CCMTA, and except for the provinces of $\mathrm{BC}$ and $\mathrm{QC}$, minimum eligibility to hold a valid driver's permit is largely dictated by criteria outlined in the CCMTA medical standards document. The CMA document was developed by Canadian physicians to guide their peers about safe driving or driving cessation independent of a patient's legal permit to drive ${ }^{8,26}$. While the CMA document acknowledges that differences between the CMA and CCMTA standards exist, there are no recommendations on how a physician should deal with these conflicts. For example, in a case where a patient meets CCMTA but not CMA fitness guidelines (e.g. a patient who has had a first unprovoked seizure with a normal EEG and normal neurologic assessment but is not three months seizure free), it is unclear whether a physician should advise patients that their medical condition disqualifies them from holding a driver's license. The lack of consistency regarding how epilepsy experts approach this common scenario is therefore predictable. Along with the inconsistency that patients experience, we are also concerned that the discrepancies between CMA and CCMTA documents may engender ambiguity and potential vulnerability for the individual physician. Physicians who strictly counsel patients according to the CCMTA document could expose themselves to 
medico-legal liability when CMA medical guidelines are not met, whereas physicians who counsel patients strictly according to CMA guidelines could expose themselves to accusations of professional misconduct if they advise patients that they are ineligible to legally drive in a situation where they meet CCMTA medical standards.

Our study has a number of methodological limitations. Firstly, the limited number of epilepsy specialists in Canada results in a small respondent sample size, after excluding ineligible participants our sample size represented $59 \%$ of the total pool. Transportation and licensure are within the domain of provincial responsibilities and because of the small sample size, our study lacked statistical power to examine physician responses at the provincial levels where the greatest expected regulatory homogeneity would be expected. This is particularly pertinent for the provinces of $\mathrm{BC}$ and $\mathrm{QC}$ where provincial regulations differ from the rest of the country. A second limitation to our study is that our survey did not explore physicians' counseling responses to determine the reasons behind their decisions and as such we can not quantify how much guidelines influence epileptologists in their practice. We are unable to sufficiently quantify the detailed knowledge of our respondents with respect to precise CMA or CCMTA guidelines, and it remains possible that our sample of physicians are not aware of all the discrepancies between the two documents for patients with seizures or epilepsy. Still, outside of the provinces of $\mathrm{BC}$ and $\mathrm{QC}$, almost as many physicians use the CCMTA document as use the CMA document in isolation suggesting to us that differences between the two Canadian documents are relevant to the variability in counseling that we have found.

The primary objective of the CCMTA Medical Standards for Drivers is "to provide guidelines to facilitate a consistent approach to driver fitness decision-making by provincial and territorial driver fitness authorities across Canada", which is reasonable given the fact that Canadians routinely move and travel across provincial and territorial boundaries. Despite the title (CMA Driver's Guide: Determining Medical Fitness to Operate Motor Vehicles), the CMA publication acknowledges that the primary role of the publication is not to determine the medical fitness of drivers (which is the government fitness authorities role) but rather to provide: "practical information about counseling patients on the effects of their state of health on their fitness to drive". Given the need to balance potential public risk against personal independence and financial costs to individuals, the management of medical fitness issues in the clinic setting are a tremendous challenge for clinicians. Our findings suggest that the presence of two conflicting national guidelines for driver fitness has a negative impact on Canadian physicians' ability to effectively manage these difficult clinical situations and that a move to a single published national document for medical fitness for drivers would be expected to improve the consistency in which Canadian physicians approach questions of driver fitness. Heavier stakeholder involvement of epilepsy experts from across Canada in the development of driver fitness guidelines could, in the future, promote improved consistency in physician counseling of seizure patients who drive.

\section{REFERENCES}

1. Gray C, Sullivan P. MDs still the key to eliminating unfit drivers, jury decides. CMAJ. 2002;166(9):1196.

2. Redelmeier DA, Vinkatesh V, Stanbrook MB. Mandatory reporting by physicians of patients potentially unfit to drive. Open Med. 2008;2(1):e8-17.

3. Redelmeier DA, Yarnell CJ, Thiruchelvam D, Tibshirani RJ. Physicians' warnings for unfit drivers and the risk of trauma from road crashes. N Engl J Med. 2012;367(13):1228-36.

4. Gilliam F, Kuzniecky R, Faught E, Black L, Carpenter G, Schrodt R. Patient-validated content of epilepsy-specific quality-of-life measurement. Epilepsia. 1997;38(2):233-6.

5. Jang RW, Man-Son-Hing M, Molnar FJ, et al. Family physicians' attitudes and practices regarding assessments of medical fitness to drive in older persons. J Gen Intern Med. 2007;22(4):531-43.

6. Marshall SC, Gilbert N. Saskatchewan physicians' attitudes and knowledge regarding assessment of medical fitness to drive. CMAJ. 1999;160(12):1701-4.

7. Canadian Council of Motor Transport Administrators. CCMTA medical standards for drivers. Ottawa (ON): The Council; 2011.

8. Canadian Medical Association. Determining medical fitness to operate motor vehicles. CMA driver's guide. 8th ed. Toronto (ON): The Association; 2012

9. Gross DW. CMA driver's guide. CMAJ. 2007;177(1):64.

10. Krumholz A. Driving issues in epilepsy: past, present, and future. Epilepsy Curr. 2009;9(2):31-5.

11. Ministry of Public Safety and Solicitor General Office of the Superintendent of Motor Vehicles. British Columbia Driver Fitness Handbook for Medical Professionals 2010. Victoria (BC) : The Ministry; 2010.

12. Règlement sur les conditions d'accès à la conduite d'un véhicule routier relatives à la santé des conducteurs : Code de la securite routiere Quebec de 2009, Pub.L. c-24.2, a.619, par.2 et 8.

13. World Health Organization. Global status report on road safety 2013: Supporting a decade of action 2013. Geneva (Switzerland): The Organization; 2013.

14. Devlin A, Odell M, L Charlton J, Koppel S. Epilepsy and driving: current status of research. Epilepsy Res. 2012;102(3):135-52.

15. King D, Benbow SJ, Barrett JA. The law and medical fitness to drive--a study of doctors' knowledge. Postgrad Med J. 1992;68 (802):624-8.

16. Kelly R, Warke T, Steele I. Medical restrictions to driving: the awareness of patients and doctors. Postgrad Med J. 1999;75 (887):537-9.

17. Drazkowski JF, Neiman ES, Sirven JI, McAbee GN, Noe KH. Frequency of physician counseling and attitudes toward driving motor vehicles in people with epilepsy: comparing a mandatoryreporting with a voluntary-reporting state. Epilepsy Behav. 2010;19(1):52-4.

18. Shareef YS, McKinnon JH, Gauthier SM, Noe KH, Sirven JI, Drazkowski JF. Counseling for driving restrictions in epilepsy and other causes of temporary impairment of consciousness: how are we doing? Epilepsy Behav. 2009;14(3):550-2.

19. Harvey P, Hopkins A. Views of British neurologists on epilepsy, driving, and the law. Lancet. 1983;1(8321):401-4.

20. McLachlan RS, Jones MW. Epilepsy and driving: a survey of Canadian neurologists. Can J Neurol Sci. 1997;24(4):345-9.

21. Andermann F, Rémillard GM, Zifkin BG, Trottier AG, Drouin P. Epilepsy and driving. Can J Neurol Sci. 1988;15(4):371-7.

22. Farquhar CM, Kofa EW, Slutsky JR. Clinicians' attitudes to clinical practice guidelines: a systematic review. Med J Austr. 2002;177: 502-6.

23. Wiebe S. Still an elusive target: guiding practice for epilepsy surgery. Neurology. 2010;75:678-9.

24. Winston GP, Jaiser SR. Western driving regulations for unprovoked first seizures and epilepsy. Seizure. 2012;21(5):371-6.

25. Eur-lex.Europa.eu. Brussels: European Union Amending Counsel Directive 91/439/EEC on driving licenses; [updated 2009 Aug 25; cited 2009 Aug 26] Available from: http://eurex.europa.eu/LexUriServ/LexUriServ.do?uri=OJ:L:2009:223:00 26:01:EN:HTML.

26. Butcher D. CMA driver's guide. CMAJ. 2007;177(1):64-5. 


\section{Appendix A: Physician Questionnaire}

\section{Driving Recommendations for Patients with Seizures}

This is a survey of epilepsy experts around Canada meant to explore their views and recommendations regarding driving in patients who have had seizures. The objective of this study is to document the variability of expert recommendations around the country involving common clinical scenarios. Your views would be greatly appreciated.

\section{DEMOGRAPHICS}

1. Do you currently have an active clinical practice in which you see patients with seizures?

- Yes

- No

2. What is your primary practice?

- $\quad$ Adult Neurology

- Pediatric Neurology

- Neurosurgery

- Other

3. Have you completed subspecialty training in epilepsy?

- Yes

- No

4. What part of Canada is your practice mainly located?

- British Columbia

- Alberta

- Saskatchewan

- Manitoba

- Ontario

- Quebec

- New Brunswick

- Nova Scotia

- $\quad$ Prince Edward Island

- Newfoundland

- Territory

- $\quad$ Other

\section{PART 1}

5. Overall, which reporting structure would you prefer for your province?

- $\quad$ Mandatory Reporting

- Discretionary Reporting

6. Using a 10-point scale, how would you rate the ease or difficulty in your practice in managing seizure patients' driving issues?

$$
\begin{array}{llllllllll}
\text { (Easy) } 1 & 2 & 3 & 4 & 5 & 6 & 7 & 8 & 9 & 10 \text { (Difficult) }
\end{array}
$$

7. In your opinion, if a patient is medically unfit to drive, they should NOT be eligible to hold a driver's license.

- $\quad$ Agree

- Disagree

8. It is the physician's role to determine whether a seizure patient is eligible to hold a driver's license.

- Agree

- Disagree

9. It is the physician's role to provide accurate information to the provincial registry but it is the registry's role to determine whether a patient is eligible to hold a driver's license.

- $\quad$ Agree

- Disagree

10. It is the physician's obligation to provide patients with accurate information regarding what rules are used by the provincial registry to determine eligibility to hold a driver's license.

- $\quad$ Agree

- Disagree

11. Regarding seizures and driving you base your discussion with patients on which of the following documents (specify as many as apply):

- $\quad$ The CMA Driver's Guide- Determining Medical Fitness to Operate Motor Vehicles

- The Canadian Council of Motor Transport Administrators Medical Standards for Drivers

- Other: 
Appendix A: 2 of 2

Scenario \#1: You are seeing a 40 year old patient with new onset epilepsy (three generalized convulsions in the last month). He has been started on antiepileptic medication and has so far been compliant and reliable.

12. You advise the patient that he is not fit to drive and is not eligible to hold a class V (i.e. standard) driver's license until he is at least 6 months seizure free.

- $\quad$ Agree

- Disagree

13. Do you advise the patient that if he does not take the medication but remains seizure free for 6 months, he is still eligible to hold a driver's license?

- Yes

- No

14. If the patient has a Class I (i.e. heavy truck) driver's license you advise the patient that he will have to be at least 5 years seizure free before he will be eligible to hold a Class I license.

- $\quad$ Agree

- Disagree

Scenario \#2: You are asked to see a patient in the ER who presented the previous night after a single unprovoked seizure. The ER staff has already arranged an EEG which was normal. The patient's neurological assessment is normal.

15. Do you advise the patient that he is currently eligible to hold a class V (standard) driver's permit?

- Yes

- No

16. You advise that patients who have experienced a single unprovoked seizure should be required to be seizure free for a period of time before they are able to drive.

- $\quad$ Agree

- Disagree

17. You advise that all patients who have experienced a single unprovoked seizure should be required to have either a CT or MRI of the head before they are able to drive.

- $\quad$ Agree

- Disagree

Scenario \#3: JME patient

18. You advise that any patient with a diagnosis of Juvenile Myoclonic Epilepsy must remain on medication in order to be able to drive, even if they have been seizure free for several years off of medication and have a normal sleep deprived EEG.

- $\quad$ Agree

- Disagree

\section{Scenario \#4: Drug Adjustments *}

19. You advise that any patient who has had medication adjustment of ANY type should be 3 months seizure-free after the change in medication before they are fit to drive.

- $\quad$ Agree

- Disagree

Scenario \#5: A patient who had been seizure free for 6 years but experienced a seizure following medication withdrawal on the recommendations of his physician has been restarted on the medication that was previously effective. *

20. You advise that a patient who has experienced seizures with medication withdrawal should be seizure free for a period of time before they should resume driving.

- $\quad$ Agree

- Disagree

Scenario \#6: You are seeing a 35 year old patient 6 months after epilepsy surgery. He has not experienced any seizures since surgery. The patient asks if it would be possible for him to drive. *

21. You advise that a patient should be at least 12 months seizure free following surgery in order to drive.

- Agree

- $\quad$ Disagree

22. You advise that this patient should have therapeutic drug levels in order to be able to drive.

- $\quad$ Agree

- Disagree 